\title{
A sarna das orelhas dos coelhos
}

ARMANDO BERGAMIN

Assistente da Seção de Avicultura e Cunicultura da Escola Superior de Agricultura "Luiz de Quelroz"

Universidade de Săo Paulo

INDICE

Introdução

Plano de trabalho

Resultados e conclusões ....... 391

Resumo e indicação ......... 391

Abstract . ................ 392

Literatura ............... 392 


\section{INTRODUÇAOO}

A sarna das orelhas ou cancro das orelhas é uma doença dcs coelhos produzida pelo ataque de um ácaro, o Psoropts communis. A doença aparece de preferência nas raças de grande porte como os Gigantes e Belier, mas pode ocorrer em qualquer raça, produzindo prejuízos sérios quando não combatida eficazmente.

A sarna aparece e toma vulto principalmente nas criações onde a limpeza deixa muito a desejar; caracteriza-se por abundante e espêssa secreção de un ou ambos os ouvidos, formando-se na face interna do pavilhão uma crosta grossa, de aspecto repugnante que vai invadindo o conduto auditivo, podendo chegar até o tímpano, perfurando-o, o que causará infalivelmente a morte.

Os coelhos doentes de sarna das orelhas ficam inapetentes, emagrecem ràpidamente, sentindo sempre coceira e dôr intensa, obrigando-os sacudir continuamente a cabeça e raspar com as unhas a base do pavilhão, produzindo ferimentos que ainda mais intensificam as dores.

O tratamento desta enfermidade é relativamente simples e de maneira geral os autores indicam como eficazes aplicações de pomadas e soluções, quase sempre de difícil preparo, em que entram o óleo de amêndoa, enxófre em pó, vaselina, sublimado corrosivo, ácido fênico, glicerina, azeite, pentasulfeto de potássio, etc.

Tendo sido verificado por nós o aparecimento dessa doença em alguns coelhos da criação da Seção de Avicultura e Cunicultura da E. S. A. "Luiz de Queiroz", resolvemos tentar a cura dos mesmos, fazendo uso de diversos ingredientes de fácil obtenção e bem ao alcance da grande maioria dos que se interessam pela criação dessa utilíssima espécie doméstica.

\section{PLANO DE TRABALHO}

Foram tomados 15 coelhos doentes, em diferentes estágios da moléstia e, ao acaso, formados 5 lotes de 3 animais, que chamaremos lotes $1,2,3,4$ e 5 , tratados respectivamente com Detefon, Inset-o-Blitz, Terebentina e oleo, D.D.T. e Querozene Os 5 lotes receberam tratamentos consecutivos, com in- 
Resumo das observações sôbre os tratamentos utilizados

\begin{tabular}{|c|c|c|c|c|c|c|}
\hline Lote & $\begin{array}{l}\text { N. }{ }^{\circ} \text { do } \\
\text { coelho }\end{array}$ & Raça & 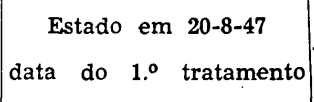 & $\begin{array}{r}\text { Estado em 24-8-47 } \\
\text { data do } 2 .^{\circ} \text { tratamento }\end{array}$ & \begin{tabular}{|ccc} 
Estado de & $29-8-47$ \\
data do $3 .^{\circ}$ & tratamento
\end{tabular} & $\begin{array}{c}\text { Estado em } 3-9-47 \\
\text { data do } 4 .^{\circ} \text { tratamento }\end{array}$ \\
\hline $\begin{array}{c}1 \\
\text { (Detefon) }\end{array}$ & $\begin{array}{r}279 \\
\mathrm{~S} / \mathrm{N} \\
251\end{array}$ & $\begin{array}{l}\text { Gigante Branco } \\
\text { Chinchila } \\
\text { Chinchila }\end{array}$ & $\begin{array}{l}\text { Fortemente atacado } \\
\text { Pouco atacado } \\
\text { Fracamente atacado }\end{array}$ & $\begin{array}{l}\text { Sensivel melhora } \\
\text { Em bom estado } \\
\text { Em bom estado }\end{array}$ & $\begin{array}{l}\text { Continua melhorando } \\
\text { Quase são } \\
\text { Quase são }\end{array}$ & $\begin{array}{l}\text { Curados com queda dos } \\
\text { pêlos. } \\
\text { Ação cáustica. }\end{array}$ \\
\hline $\begin{array}{l}\quad 2 \\
\text { (Insect-o- } \\
\text { Blitz) }\end{array}$ & $\begin{array}{l}118 \\
135 \\
108\end{array}$ & $\begin{array}{l}\operatorname{Rex} \\
\text { Rex } \\
\text { Gigante Branco }\end{array}$ & $\begin{array}{l}\text { Regularmente atacado } \\
\text { Fortemente atacado } \\
\text { Fortemente atacado }\end{array}$ & $\begin{array}{l}\text { Bôa melhora } \\
\text { Bôa melhora } \\
\text { Bôa melhora }\end{array}$ & $\begin{array}{l}\text { Bons, porém } \\
\text { com a pele } \\
\text { causticada }\end{array}$ & $\begin{array}{l}\text { Curados com queda dos } \\
\text { pêlos. } \\
\text { Ação cáustica. }\end{array}$ \\
\hline $\begin{array}{c}\text { 3 } \\
\text { (Terebentina } \\
\text { e óleo) }\end{array}$ & $\begin{array}{l}123 \\
258 \\
120\end{array}$ & $\begin{array}{l}\text { Gigante Preto } \\
\text { Gigante Branco } \\
\text { Gigante Branco }\end{array}$ & $\begin{array}{l}\text { Regularmente atacado } \\
\text { Fracamente atacado } \\
\text { Regularmente atacado }\end{array}$ & $\begin{array}{l}\text { Melhora notável } \\
\text { Melhora notável } \\
\text { Melhọa notável }\end{array}$ & $\begin{array}{l}\text { Os } 3 \text { em muito bom } \\
\text { estado } \\
\text { Quase curados }\end{array}$ & $\begin{array}{l}\text { Curado. } \\
\text { Curado. } \\
\text { Curado. }\end{array}$ \\
\hline $\begin{array}{cc}4 & \\
\text { (D.D.T. } & \mathrm{e} \\
\text { vaselina } & \mathrm{a} \\
10 \% \text { ) } & \end{array}$ & $\begin{array}{r}S / N \\
117 \\
129\end{array}$ & $\begin{array}{l}\text { Chinchila } \\
\text { Rex } \\
\text { Gigante Branco }\end{array}$ & $\begin{array}{l}\text { Regularmente atacado } \\
\text { Regularmente atacado } \\
\text { Fracamente atacado }\end{array}$ & $\begin{array}{l}\text { Curado } \\
\text { Muito melhor } \\
\text { Muito melhor }\end{array}$ & $\begin{array}{l}\text { Completamente curados. } \\
\text { Não foi feito curativo. }\end{array}$ & $\begin{array}{l}\text { Completa e } \\
\text { eficazmente } \\
\text { curados. }\end{array}$ \\
\hline $\begin{array}{c}5 \\
\text { (Querozene) }\end{array}$ & $\begin{array}{l}159 \\
196 \\
277\end{array}$ & $\left\{\begin{array}{l}\text { Rex } \\
\text { Gigante Branco } \\
\text { Gigante Branco }\end{array}\right.$ & $\begin{array}{l}\text { Fortemente atacado } \\
\text { Fortemente atacado } \\
\text { Regularmente atacado }\end{array}$ & $\begin{array}{l}\text { Bôa melhora } \\
\text { Bôa melhora } \\
\text { Bôa melhora }\end{array}$ & $\begin{array}{l}\text { Curado } \\
\text { Curado } \\
\text { Pouca sarna no pescoço } \\
\text { e cachaço }\end{array}$ & $\begin{array}{l}\text { Curados, com queda de } \\
\text { pêlos. } \\
\text { Ação cáustica. }\end{array}$ \\
\hline
\end{tabular}


tervalos de quatro dias. Todos os coelhos foram submetidos, durante o tempo do tratamento, à mesma alimentação e aos mesmos cuidados, ficando alojados em baias individuais da coelheira.

Os coelhos, no início do tratamento, foram sujeitos a cuidadosa limpeza, com remoção das crostas do pavilhão da orelha, limpeza essa feita o mais profundamente possivel, afim de facilitar a ação dos medicamentos.

\section{RESULTADOS E CONCLUSÓES}

Pelo exame do quadro acima pode-se notar que, de maneira geral, todos os tratamentos foram de ação eficaz contra o ataque do Psoropts communis. Todavia o Detefon, o Insect-oBlitz e o Querozene, além de terem exercido ação um pouco mais lenta, apresentaram $o$ inconveniente de agirem como cáusticos, prejudicando sensivelmente o pêlo das regioes vizinhas às orelhas.

O tratamento com Terebentina e óleo apresentou resultados muito bons. pois os coelhos foram melhorando gradativamente e no $4 .^{\circ}$ curativo todos estavam completamente curados e sem nenhum sinal de prejuizo para os pêlos. Este resultado não constituiu novidade, porquanto o tratamento já havia sido por nós provado anteriormente com o mesmo éxito.

O D. D. T. a $10 \%$ e vaselina foi o tratamento mais eficaz, pois com duas aplicações apenas curou radicalmente a sarna sem deixar vestígios nos pêlos.

Para comprovar o efeito benéfico e radical do $D$. D. T., tomámos 3 coelhos atacados e com a doença em adiantado estágio; as orelhas estavam inteiramente invadidas pelas crostas, com pústulas que exalavam acentuado máu cheiro. Feita a limpeza e a primeira aplicação de D. D. T., notámos uma rápida melhora. O segundo curativo fol feito 4 dias depois e o; coelhos ficaram completamente sãos.

Ficou evidenciado assim que a aplicação de D. D. T. conslitui um tratamento muito eficaz e portanto recomendável.

\section{RESUMO E INDICAÇAO}

A experiência foi realizada com o propósito de encontrar um tratamento eficaz e de fácil aplicação na cura da sarna das 
orelhas do coelho doméstco. Foram tomados 5 lotes de 3 coelhos e tratados com Detefon, Insect-o-Blitz, Terebentina e óleo, D. D. T. a $10 \%$ e vaselina e Querozene. Foram feitas 4 aplicações com intervalos de 4 dias.

Chegámos à conclusão de que o melhor tratamento foi 0 D. D. T. a $10 \%$ e vaselina que produziu os melhores resultados c que pode, por isso, ser indicado.

A terebentina e óleo também pode ser indicada como eficiente.

Quanto aos outros tratamentos é possível que produzam cfeitos satisfatórios fazendo-se uma diluição conveniente, afim de atenuar a ação causticante das ingredientes.

\section{ABSTRACT}

This paper deals with the results obtained in one experiment with rabbits, made in order to see which treatment should be the best one against ear canker.

Five treatments, each one with 3 rabbits, were tried : Deteion, Insect-0-Blitz, Turpentine with oil, DDT with $10 \%$ of vaseline and Kerozene.

The best results were obtained with DDT-10\% and vaseline-90\% which proved to be more efficacious, saving the animals quickly than the other treatment.

\section{LITERATURA}

1) BETTENCOURT, J. - sem data - Criação dos Coelhos e Indústria das Peles. Lisboa.

2) BRILLAT, A. - sem data - La Cria Industrial del Conejo - Barcelona.

3). CREsPO, R. J. - 1930 - Conejos y Conejares. Madrid.

4) LICCIARDELLI, G. e CORTESE, M. - 1945 - Coniglicoltura Pratica. Milano.

5) SPAGNOLI, M. - 1946 - L'allevamento de la Lana del Coniglio Angora. Milano. 